\title{
Title of the special issue: Perspective solutions of electronic systems supporting the development of carbon-free mobility
}

\author{
Michal Frivaldský ${ }^{1}$
}

Published online: 16 November 2021

(c) The Author(s), under exclusive licence to Springer-Verlag GmbH Germany, part of Springer Nature 2021

This special issue of Electrical Engineering-Archiv fur Elektrotechnik, is focused on research and development of solutions as well as technologies that can accelerate the integration of electromobility into everyday life. The papers are extended versions of the contributions presented at the ELEKTRO 2020 conference held from 25 May to 28 May 2020, in Taormina, Sicily. Due to pandemic restrictions, which came into effect for the first time, the conference was realized as an online event, with more than 120 conference participants and over 100 scientific contributions focusing on a broad spectrum of topics: computing and information technology, power electronics and energy systems, materials and technologies, biomedical engineering, robotics, cybernetics, and mechatronics. This special issue includes a selection of papers primarily focused on electrical engineering and power electronics.

We hope that the papers in this special issue will inspire and support scientists and researchers in solving problems and developing topics across broader horizons. Even today, it can be said that the research priority is clearly the energy efficiency of power electronic systems, electrical machines, electric drives, and energy storage systems. All these trends clearly support the development of green mobility and contribute to the research and development of progressive and promising solutions. The papers collected in this special issue show the ongoing research and development effort in the field of thermal performance optimization of power converters utilizing wide-bandgap devices, control methods, and techniques for the switched-mode power supplies. Very important topic is represented by battery technology, particularly the estimation of optimal energy flow control, lifetime estimation, and reliability assessments. Moreover, a critical review is provided for the analysis of discrete choice models of electric vehicle owners. It is hoped that those interested in current research trends in electrical machines will find the contributions related to optimal construction of switched reluctance motor and to sensorless control of electric drives useful.

A special thanks go to guest editors Mario Cacciato and Giovanni Nobile, the authors, the reviewers, and those who contributed and prepared this issue of Electrical Engineering-Archiv fur Elektrotechnik.

On behalf of the organizing and scientific committee of the ELEKTRO 2020 conference.

\section{Michal Frivaldský}

Publisher's Note Springer Nature remains neutral with regard to jurisdictional claims in published maps and institutional affiliations.
Michal Frivaldský

michal.frivaldsky@feit.uniza.sk

1 Department of Mechatronics and Electronics, Faculty of Electrical Engineering and Information Technologies, University of Zilina, Zilina, Slovakia 